\title{
A PROPOSED TECHNOLOGY SOLUTION FOR PREVENTING MARINE LITTERING BASED ON UAVS AND IOT CLOUD-BASED DATA ANALYTICS
}

\author{
George Stengos ${ }^{1}$, Stavros T. Ponis ${ }^{2}$, George Plakas ${ }^{2}$ and Athanasios Yamas ${ }^{3}$ \\ ${ }^{1}$ CycleFi IKE, Melissou 24, Athens 11635, Greece \\ ${ }^{2}$ National Technical University Athens, Heroon Polytechniou 9, Zografos 15780, Athens, Greece \\ ${ }^{3}$ Altus LSA, Renieri 9, Chania 73134, Greece
}

\begin{abstract}
Pollution in the marine environment is a global problem with severe consequences on marine and terrestrial ecosystems and to human health. It is estimated that every year, eight million tonnes of debris find their way into the world's oceans, mostly consisted of valuable materials which by following land-based routes are finally finding their way into the sea, instead of being recycled and reused, thus disrupting the Circular Economy value circle. Especially in the case of shorelines, which are in the spotlight of the research presented in this paper, fifty to eighty percent of the rejected debris is made of plastic. The research presented in this paper prescribes an innovative technology solution with the potential of mitigating the severity of the marine littering problem. The proposed solution utilizes the combined power of two emerging Industry 4.0 technologies, i.e. UAVs (Unmanned Aerial Vehicles) and Sensor technology. These two technologies are integrated in a proposed technology system capable of data collection, analysis and presentation through a cloud based platform of software services available to all system users and stakeholders. Furthermore, the proposed solution will provide tools for facilitating and triggering the pro-active role of responsible citizens, while creating a societal consensus through a user friendly and gamified citizens' awareness platform.
\end{abstract}

\section{KEYWORDS}

Circular Economy, Marine Littering, Blue Growth, Internet of Things, Unmanned Aerial Vehicles, Wireless Sensor Networks, Gamification

\section{INTRODUCTION}

Marine pollution is a severe global problem, which is getting worse as millions of tons of waste end up in the oceans every year causing multiple environmental, economic, health and aesthetic concerns with serious implications (Gallo et al., 2018). Apparently, the way products and goods are currently discarded fails to capture the economic benefits of a more 'circular' approach and harms the environment. In fact, marine litter is clearly a demonstration of a resource inefficient economy. Valuable materials are polluting beaches and damaging the environment instead of returning into the economy (Newman et al., 2015). In that sense, European and international directives and legislative pressures have been set forth to figure out ways to tackle the challenges of marine littering. Therefore, a Circular Economy approach, which puts the emphasis on preventing waste and on reuse of materials and products in the first place, seems the most efficient solution to the marine litter problem (Eriksen et al., 2017). Until today, estimations on marine littering seem to be in an assumption-based approach, making it nearly impossible to provide an exact measurement, due to the lack of a worldwide systematic monitoring mechanism. In fact, the lack of systematic monitoring of the origin, patterns and distribution of plastic waste ending up in the marine environment, results to the absence of a worldwide prevention mechanism (Borrelle et al., 2017).

Currently, there is very limited information from existing studies regarding the inland flow of the plastic marine litter. (ibid) So far, large land-based sources of marine litter include waste coming from landfills located near coastal zones or on the banks of rivers, ports, touristic and recreational activities taking place at the coasts and food packaging, which is the most common category of discarded materials directly associated with recreational activities (Mouat et al., 2010). Although the clean-up of the sea is imperative, the 
prevention of marine littering from debris entering the sea, remains the top priority. However, the lack of public awareness related to marine littering and best practices for waste disposal exacerbates the situation (Hasan, 2004). Unfortunately, up to today current efforts seem inadequate and inefficient since they are traditionally limited to high cost campaigns to raise awareness on marine littering and responsible citizenship. It is now clear to policymakers that they will not be able to tackle the marine littering challenge in an effective, impactful and cost-efficient manner, unless increased and ongoing citizens' participation is safe guarded (UNEP, 2018). In that direction, a cost-effective awareness program that creates a positive citizens' experience to maintain ongoing engagement for prevention of marine littering, seems an imperative.

As a solution, in this paper, the authors propose an integrated technology solution, which utilizes state of the art technologies such as drones, IoT wireless sensors, and mobile station centers in one cloud-based platform solution, launching and landing drones to prevent and/or divert debris from entering the marine environment while at the same time providing services to both public authorities (i.e. municipalities) and citizens inhabiting coastal areas. Furthermore, the proposed technology aims to promote the active role of responsible citizens, enhancing awareness and empowering the pro-active role of local policy to reduce marine pollution in general. In doing so the introduction of a 'Serious' Game is proposed, that plays a central role in the adoption, acceptance and sustainability of the system, by a) attracting beach management authorities to adopt the solution and creating a network of participants that gain visibility and recognition with the introduction of an eco-label similar to the well stablished 'Blue Flag' label and b) activating as many citizens as possible through raining awareness actions and making them part of the ecosystem by giving and receiving real-time information on the current environmental status of the beach (e.g. uploading a photograph of stacked plastics that need to be collected before they enter the sea) and participating in information / education programs on recycling / cyclical economy issues and conscious recycling behavior.

The proposed solution is in line with the European Strategy for Plastics (16/01/2018/EU) (European Commission, 2018) and the actions of the European Union, in the areas of Blue and Circular Economy for the design and successful implementation of innovative technological solutions that support the recording of quantities and the identification of sources of marine pollution from plastic waste.

\section{THE PROPOSED SOLUTION}

The proposed solution involves the development of network of wireless sensors operating on a LPWAN (Low Power Wide Area Network) such as LoRa (https://lora-alliance.org/), a set of integrated modules utilizing UAVs with imaging sensors supported by a mobile land-based station (van) and a specialized cloud platform for the reporting of results to system users. More specifically, The Monitor \& Detect module is responsible for identifying and monitoring the various land sources of marine debris, while calculating the disposed quantities and recording their catchment areas in the marine environment. For these purposes, the configurable UAS (Atlas 8) drone model is proposed, equipped with powerful optical sensors, state of the art thermal sensors, dual optical payloads and environmental sensors (www.freeflysystems.com/alta-8). Next the Collect module will provide $24 / 7$ autonomous drones by supplying a mobile land-based station van. The drones will carry out the assigned tasks, such as monitoring and detecting any kind of debris in the marine environment, before landing back on the mobile land-based station vans. Once landed, the drones are recharged and made ready for the next flight, whilst field data is transmitted wirelessly (through nG/GPRS) back to the cloud central server. This kind of all-encompassing solution appears to be the way forward in connecting drones to a wider Internet of Things array, while the ability to recharge and be maintained on the station pad could further lessen human involvement paving the way for a fully autonomous future operation. The Aggregation \& Filtering module will provide users with an advanced data analysis tool and an integrated monitoring system. The abundance of data from thermal and optical cameras, video $\&$ audio sensors etc., received from the station will be analyzed with the use of an algorithm developed and run on the MongoDB, NoSQL database. The Report \& Process Center will serve as an integrated content management system, customized for the efficient storage, management, archiving, processing and logging of multimedia/heterogeneous content through a modular architecture. The platform will be capable of providing data to all involved operators with authorized access, so they can manage data in tabular form. A dashboard (e.g. Jasper Reports) will be used for monitoring and reporting purposes. Finally, the Engagement Module will provide tools for facilitating and triggering the pro-active role of 'Responsible Citizens', while creating a 
societal consensus through a friendly responsible citizens awareness platform. The platform will constitute a user-friendly interface, implementing two core functionalities, namely a) inform all citizens (recreational users and residents) through a real time debris value calculator algorithm, on the marine debris status of a selected area, providing key metrics corresponding to the environmental impact on the specific area and b) promote the "Responsible Citizen" role to manage their waste by encouraging the proper procedure of sorting/throwing away garbage and stimulating behavioral change to prevent marine littering.

The platform will integrate data into a gamified environment to enable goals' attainment. The gamification mechanism will be centered around a set of competition scenarios among the municipalities adopting the proposed solution. Leaderboards and ranking will be displayed through self-sufficient solar powered screens, which will announce performance related information. The authors believe that influencing citizens to get more involved and educated on marine littering challenges, albeit important, is not a sufficient solution. As citizens undoubtedly play an integral part in the success of tacking marine littering challenge, a gamified, engaging, citizens-focused approach with an element of social pressure is the answer that can potentially boost citizen's responsibility, promote the desired behavior effectively, and maintain a serious, profound and long-term commitment to both coastal and marine environment. A schematic of the proposed solution is presented in Figure 1.

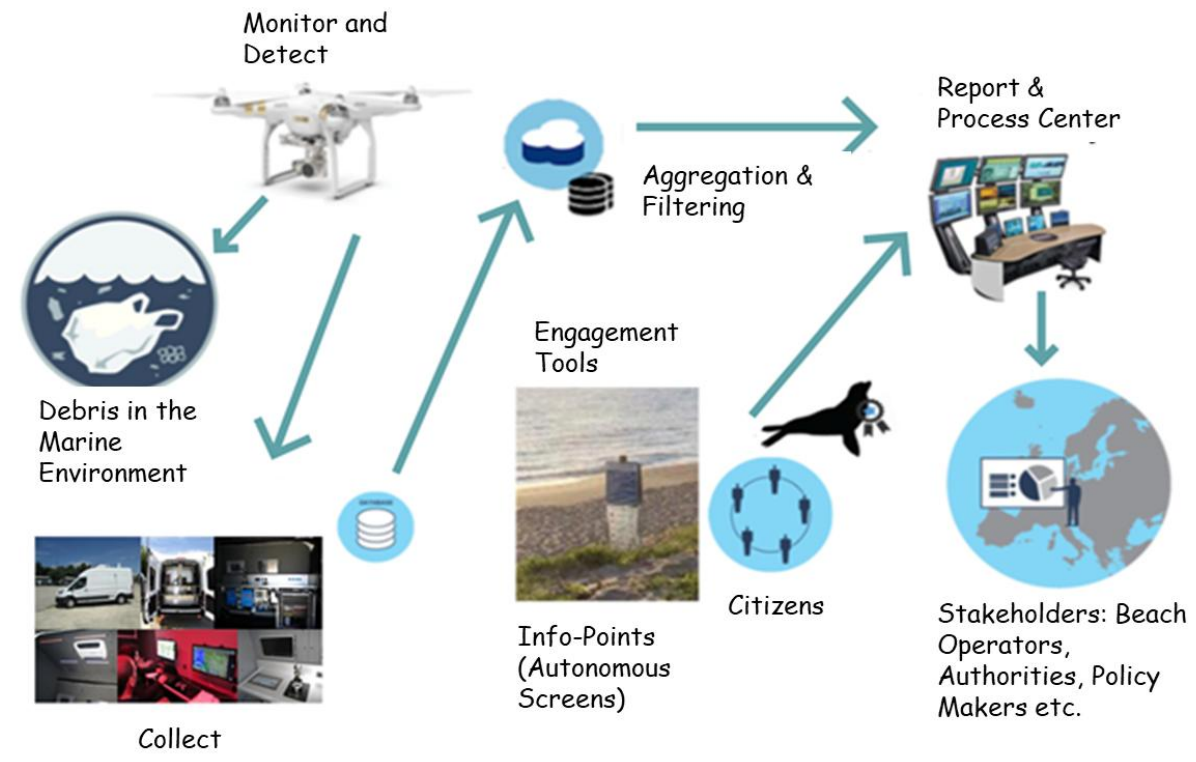

Figure 1. The proposed technology solution

The authors are currently in the phase of assessing the technical viability of the system and testing of its technological performance and underlying key components while at the same time identifying possible ways for conceptual design improvements. Their future objective is to produce a small-scale but fully customized and pilot tested Proof of Concept [POC] of a First of a Kind [FOAK] integrated infrastructure of product, service and business model including:

- A heavy-lift, multi-rotor Unmanned Aerial Vehicle [UAV] platform,

- A collection of State-of-the-art Sensors,

- A mobile land-based station (van)

- An advanced data analytics S/W for a holistic marine littering measurement \& monitoring system

- A fully integrated Web Reporting tool for the users of the system, able to analyze streaming data from the UAVs and produce meaningful and customized results, e.g. Dashboard Designer

- A system integrated Serious Game that promotes environmental awareness of marine pollution and engages citizens into helping to reduce it.

- A novel debris value calculator able to determine, in real time, key metrics corresponding to the environmental impact of the most common marine debris. 


\section{CONCLUSION}

The proposed solution aspires to promote the preservation of marine and coastal ecosystems and aims to be an ideal turnkey solution for coastlines and beaches that are willing to tackle the problem of marine littering. In doing so, it provides a reliable monitoring and gamified solution that drives competitive advantage and greater outcomes through enabling superior Citizen Engagement, while diverting debris away from marine environment. The proposed solution is improving the innovation capacity in the field of anti-marine littering technology systems, by leveraging the power and participation of citizens and enhancing their effectiveness and reliability. In terms of environmental long-term sustainability, the proposed solution accelerates the shift to a sustainable future and adds a people-driven dynamic, transforming the current efforts to raise awareness on marine littering and responsible citizenship, in which citizens passively receive information, to a two-way flow of information where citizens contribute on marine littering prevention, resulting in significant social and -above all- environmental positive impact.

\section{ACKNOWLEDGEMENT}

This research has been co-financed by the European Union and Greek national funds through the Operational Program Competitiveness, Entrepreneurship and Innovation, under the call RESEARCH - CREATE - INNOVATE (project code: T1EDK-05095).

\section{REFERENCES}

Borrelle, S., Rochman, C., Liboiron, M., Bond, A., Lusher, A., Bradshaw, H. and Provencher, J. (2017). Opinion: Why we need an international agreement on marine plastic pollution. Proceedings of the National Academy of Sciences, 114(38), pp.9994-9997.

Eriksen, M., Thiel, M., Prindiville, M. and Kiessling, T. (2017). Microplastic: What Are the Solutions?. The Handbook of Environmental Chemistry, Springer Open, pp.273-298.

European Commission - European Commission. (2019). EU Plastics Strategy. [online] Available at: https://ec.europa.eu/commission/news/eu-plastics-strategy-2018-nov-20_en [Accessed 1 Apr. 2019].

Freefly Systems. (2019). Freefly ALTA 8 - Multirotor Camera Drone for Cinematographers. [online] Available at: https://freeflysystems.com/alta-8 [Accessed 1 Apr. 2019].

Gallo, F., Fossi, C., Weber, R., Santillo, D., Sousa, J., Ingram, I., Nadal, A. and Romano, D. (2018). Marine litter plastics and microplastics and their toxic chemicals components: the need for urgent preventive measures. Environmental Sciences Europe, Volume 30, No. 1.

Hasan, S. (2004). Public Awareness Is Key to Successful Waste Management. Journal of Environmental Science and Health, Part A, Vol 39, No 2, pp.483-492.

Lora-alliance.org. (2019). Home page | LoRa Alliance. [online] Available at: https://lora-alliance.org/ [Accessed 1 Apr. 2019].

Marine plastic debris and microplastics: global lessons and research to inspire action and guide policy change. (2018). Nairobi: United Nations Environment Assembly of the United Nations Environment Programme. Available at: https://papersmart.unon.org/resolution/uploads/unep_aheg_2018_1_inf_4_unea2_edited.pdf [Accessed 1 Apr. 2019].

Mouat, J., Lopez Lozano, R. and Bateson, H. (2010). Economic Impacts of Marine Litter. [ebook] KIMO (Kommunenes Internasjonale Miljøorganisasjon). Available at: http://www.kimointernational.org/wp/wpcontent/uploads/2017/09/KIMO_Economic-Impacts-of-Marine-Litter.pdf [Accessed 1 Apr. 2019].

Newman, S., Watkins, E., Farmer, A., Brink, P. and Schweitzer, J. (2015). The Economics of Marine Litter. Marine Anthropogenic Litter, Springer Open, pp.367-394. 